\title{
CYTOTAXONOMY OF FOUR FLORAL VARIANTS OF IMPATIENS BALSAMINA L.
}

\author{
CHANDAN KUMAR DASH, MD. HARUN AR RASHID, SYEDA SHARMEEN SULTANA AND \\ M. OLIUR RAHMAN* \\ Department of Botany, University of Dhaka, Dhaka-1000, Bangladesh
}

\begin{abstract}
Karyomorphological characters were investigated in four floral variants of Impatiens balsamina L. viz. white, pink, violet and red for proper characterization and inferring relationships among them. All four floral variants of I. balsamina were found to possess $2 \mathrm{n}=14$ chromosomes, and 'Simple Chromocenter Type' of interphase nuclei was observed in all variants with many small heterochromatin blocks after orcein staining. 'Continuous Type' of prophase chromosomes was found in red variant, whereas both 'Continuous and Gradient Type' were found in other three variants. The red variant could easily be distinguished from the remaining three variants by total chromosome length, centromeric formula, average chromosome length, total form value, and karyotype asymmetry plus symmetry index. Based on karyomorphology, the white, pink and violet variants of I. balsamina were found very closely related and constituted with similar genome, whereas red variant was found to possess slightly modified genome and distinct from other three floral variants.
\end{abstract}

Key words: Cytotaxonomy, Karyomorphology, Asymmetric indices, Impatiens balsamina L.

\section{INTRODUCTION}

Impatiens balsamina L., commonly known as rose balsam or garden balsam, belonging to the family Balsaminaceae is distributed in North America, Africa, Asia and Europe (Willis 1973). This species is commonly used as ornamental plants due to possessing attractive flower colors such as white, pink, violet and red. Presence of three anthocyanidins viz. pelargonidin, peonidin and malvidin might be responsible for different pigmentations in this species. However, there is no available report on correlation between these pigmentations with genetic structure (Meenu et al. 2015). Traditionally, the whole plant is used in the treatment of thorn or glass-puncture wounds, abscesses, carbuncles, rheumatism, fractures, dysentery, superficial infections, tumor and puerperal pain (Kang and Moon 1992, Yang et al. 2001, Sakunphueak and Panichayupakaranant 2012). The dried plant is also used either in the form of tea (boiled with water) for treatment of systemic bacterial and fungal infections or used externally on the skin or nails in a plaster form to treat local infections (Lee and Lee 2010, Kim et al. 2011). Impatiens species are extremely variable and difficult to identify and characterize morphologically due to similar characters. When morphological approaches fail to identify the species or varieties in that case some other approaches viz. cytological studies offer powerful tool to overcome this constraint and proper identity of taxa (Pico and Dematteis 2014, Kaur 2018). Since four floral variants are evident in $I$. balsamina and these variants cannot be distinguished easily without flower color it is necessary to investigate and identify these floral variants employing some other tools, such as cytology and cytogenetics, as chromosome number and additional karyotypic features provide more precise information about a species.

The importance of cytological studies is manyfold, and even simple chromosome counts quite often add grander value for recognizing the distinctness of a species (Love and Love 1966). Karyosystematics is well established as one of the most important parameter in determination of the genetic relationship and degree of divergence among species or populations (Guerra 2008). The nature of interphase nuclei,

*Corresponding author. Email: <prof.oliurrahman@gmail.com>/<oliur.bot@du.ac.bd>. 
prophase and metaphase chromosomes, such as different stages of mitotic cell division also share useful information about the genome of that species. The karyomorphological analysis enables to characterize even different forms and varieties of a species (Dash et al. 2017).

Previous studies revealed that Impatiens balsamina possess different chromosome numbers (Sharma 1970, Govindarajan and Subramanian 1986, Huang et al. 1989). Various reports regarding somatic chromosome number indicated the presence of different cytotypes of this species which might be originated through different types of chromosome aberrations, thus this species gains interest for cytogenetical study. Though several authors paid attention in counting the chromosome number for Imapatiens balsamina (Sharma 1970, Chaterjee and Sharma 1970, Raghuvanshi and Mahajan 1982, Iwatsubo and Naruhashi 1999, Momtaz et al. 2007), and a cytotaxonomic study on five species of Impatiens [e.g. I. javensis Steud., I. platypetala Lindl., I. radicans Zoll., I. kinabaluensis S. Akiyama \& H. Ohba and $I$. choneceras Hassk. (wrongly spelled as 'chonoceras')] was carried out from Java and Borneo (Ikeda et al. 2005), no such study was made on Impatiens balsamina so far. Since four floral variants of Impatiens balsamina, viz. white, pink, violet and red are found in nature and there is complexity among these variants, it is important to examine these floral variants using cytological investigation. Therefore, the present study aimed at investigating different cytological characters for proper identification and characterization of the floral variants of Impatiens balsamina available in Bangladesh, and to evaluate these characters as taxonomic tool for inferring relationships among these variants.

\section{MATERIALS AND METHODS}

Four floral variants of Impatiens balsamina L., viz. white, pink, violet and red variants were collected and maintained in the Botanic garden, Department of Botany, University of Dhaka,
Bangladesh. The plant specimens were critically studied morphologically and identified with special reference to taxonomic values (Ahmed et al. 2008).

For cytological study, healthy roots were collected and pre-treated with 8hydroxyquinoline $(0.002 \%)$ for $1 \mathrm{~h}$ at $18{ }^{\circ} \mathrm{C}$ followed by $15 \mathrm{~min}$ fixation in $45 \%$ acetic acid at $4{ }^{\circ} \mathrm{C}$ and preserved in $70 \%$ alcohol for further use. They were then hydrolyzed in a mixture of $1 \mathrm{~N} \mathrm{HCl}$ and $45 \%$ acetic acid $(2: 1)$ at $65{ }^{\circ} \mathrm{C}$ for $2 \mathrm{~min}$. The root tips were stained and squashed in $1 \%$ aceto-orcein for $2 \mathrm{~h}$ (Sultana et al. 2011). Afterwards, these slides were observed under a compound microscope (Nikon eclipse 100). The well spread and clear mitotic metaphase chromosomes were taken to analyze different karyotypic parameters. Centromeric formula was determined based on the position of centromere and the number of chromosomes (Levan et al. 1964). Different karyo-morphological parameters, asymmetry and symmetry indexes were calculated, such as range of chromosomal length, total chromosome length, average chromosome length, total form (TF value) percent (Huziwara 1962), mean centromeric asymmetry (Peruzzi and Eroglu 2013), karyotype asymmetry index (Arano 1963), karyotype symmetry index (Greilhuber and Speta 1976), intrachromosomal and interchromosomal asymmetry index (Zarco 1986), degree of asymmetry of karyotypes (Watanabe et al. 1999) and karyotypes category (Stebbins 1971).

\section{RESULTS}

\section{TAXONOMIC EVALUATION}

Impatiens balsamina L., Sp., Pl. : 938 (1753). Synonym: Impatiens cornuta L. (1753) (Fig. 1).

An erect, annual, succulent herb, pubescent or glabrate, attaining up to $100 \mathrm{~cm}$ tall. Leaves are usually simple, alternate, sometimes lowest ones opposite, up to $13 \mathrm{~cm}$ long; leaf blade lanceolate or elliptic, both surfaces glabrous or sparsely pubescent, lateral veins 4-6 pairs, margin serrate. 
Inflorescences 1-3 flowered. Flowers are single cup-shaped or double camellia-like shaped, white, pink, violet and red in color, axillary, pubescent; pedicels up to $2 \mathrm{~cm}$ long, densely pubescent. Stamens 5, with linear filaments and ovoid anthers. Ovary fusiform, densely pubescent. Fruits are capsules, ellipsoid and narrowed at both ends, tomentose, with rigid yellow bristles, 1-2 cm long. Seeds are globose, tubercled and $0.4-0.6 \mathrm{~cm}$ in diameter. Flowering and fruiting period: March to October.

A comparative morphological account of taxonomic importance in four floral variants of Impatiens balsamina is summarized in Table 1.

\section{CYTOLOGICAL INVESTIGATION}

Somatic chromosome number and karyomorphology

In the present study, four floral variants, i.e. white, pink, violet and red variants of Impatiens balsamina were found to possess $2 n=14$ chromosomes (Fig. 2). The centromeric formulae of white, pink and violet variants were $10 m+4 s m$, whereas $8 m+6 s m$ was observed in the red variant (Fig. 3). The individual chromosomal length ranged from 3.10-4.62 $\mu \mathrm{m}$ in white variant, $2.73-5.17 \mu \mathrm{m}$ in pink, 2.87-5.28 $\mu \mathrm{m}$ in violet, and $3.49-5.65 \mu \mathrm{m}$ in red variant. The total chromosome length was found nearly similar in white $(54.25 \pm 2.09 \mu \mathrm{m})$, pink $(54.82 \pm 3.14 \mu \mathrm{m})$ and violet variants $(56.03 \pm 3.32$ $\mu \mathrm{m})$, while larger in red variant $(64.25 \pm 1.56$ $\mu \mathrm{m})$.

The average chromosomal length was found to be bigger in red variant than those of white, pink and violet variants. Karyotype asymmetry was higher in red variant $(59.42 \%)$ and relatively lower in white $(56.72 \%)$, pink $(55.62 \%)$ and violet variants $(55.82 \%)$. In contrast, karyotype
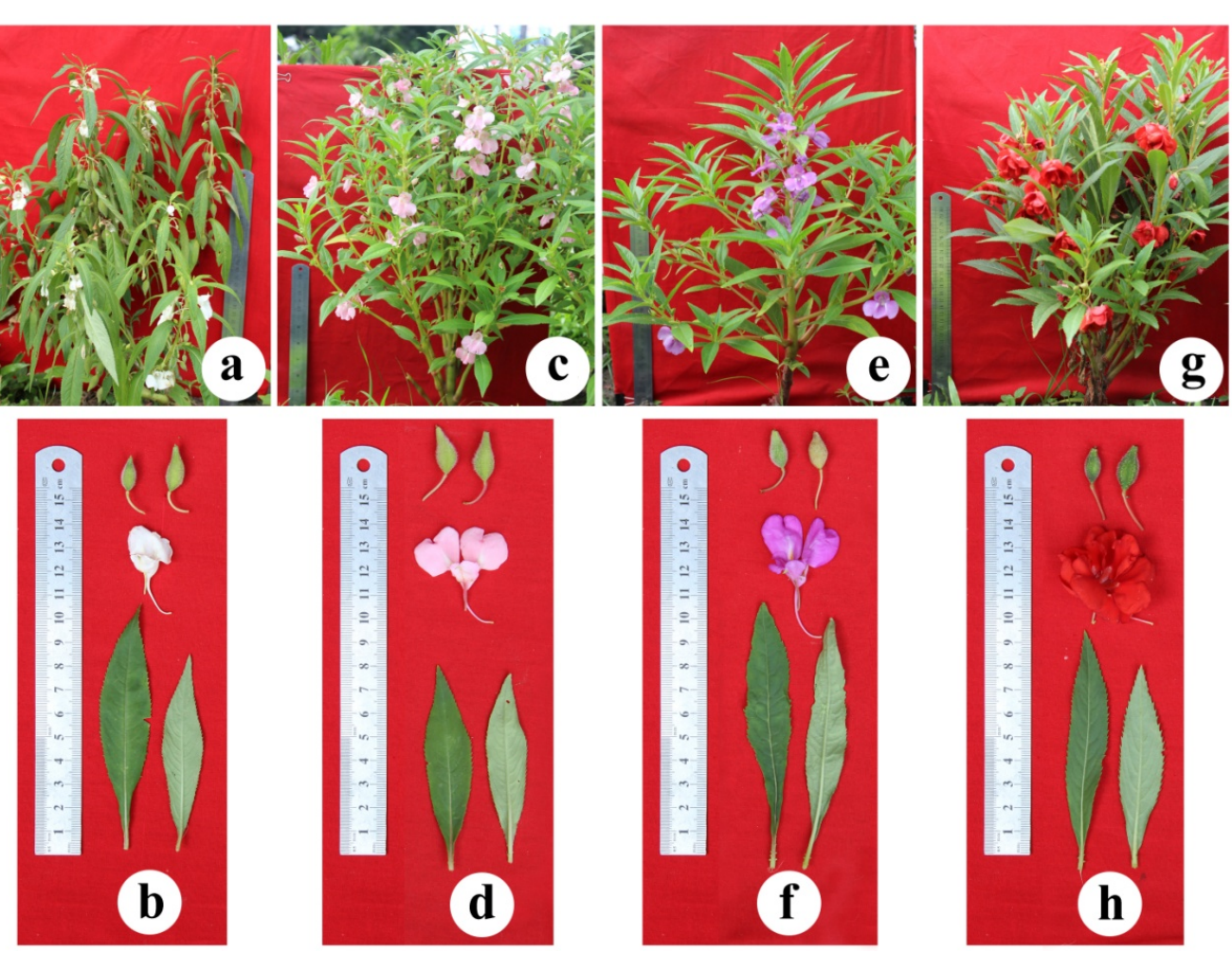

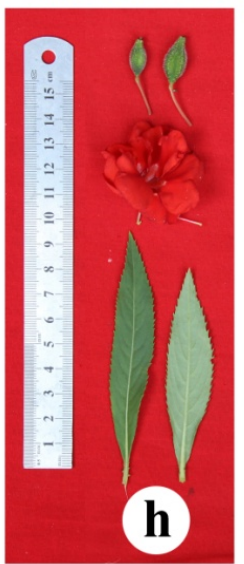

Fig. 1. Plant morphology of four floral variants of Impatiens balsamina L. (a) Habit of white variant; (b) Leaves, flower and pods of white variant; (c) Habit of pink variant; (d) Leaves, flower and pods of pink variant; (e) Habit of violet variant; (f) Leaves, flower and pods of violet variant; (g) Habit of red variant; (h) Leaves, flower and pods of red variant. 
symmetry was found lower in red variant $(68.28 \%)$ and relatively higher in white (76.31\%), pink (79.80\%) and violet variants (79.15\%). The mean centromeric asymmetry in white, pink, violet and red variants was observed as $12.36,11.15,11.43$ and 18.06 , respectively. Total form (TF) value among these types ranged from $40.58 \%$ to $44.38 \%$. The intrachromosomal asymmetry index and interchromosomal asymm- etry index were found same in pink variant, however, the former was higher than the latter in white and red variants, but lower in violet variant. In the red floral variant of I. balsamina, the degree of asymmetry of karyotype was higher than the remaining three variants (Table 2). No satellite was observed in these four floral variants. Karyotypes of all these four variants could be categorized as ' $1 \mathrm{~A}$ '.

Table 1. Comparative morphological account of taxonomic importance among four floral variants of Impatiens balsamina $\mathbf{L}$.

\begin{tabular}{|c|c|c|c|c|}
\hline Characters & White & Pink & Violet & Red \\
\hline Plant height $(\mathrm{cm})$ & $50-75$ & $60-80$ & $60-85$ & $70-90$ \\
\hline Leaf size $(\mathrm{cm})$ & $6-12 \times 1.5-2.5$ & $6-11.5 \times 1.5-2$ & $7-15 \times 1.5-2.5$ & $9-16 \times 2-3$ \\
\hline Leaf shape* & Lanceolate & Lanceolate & Lanceolate & Lanceolate to elliptic \\
\hline Stem color & Green & $\begin{array}{l}\text { Green, light } \\
\text { reddish stripe } \\
\text { present at the base }\end{array}$ & $\begin{array}{l}\text { Green, reddish } \\
\text { stripe present at } \\
\text { the base }\end{array}$ & $\begin{array}{l}\text { Green, reddish stripe } \\
\text { present at the base }\end{array}$ \\
\hline Stem nature & $\begin{array}{l}\text { Erect, sparsely } \\
\text { branched }\end{array}$ & $\begin{array}{l}\text { Erect, sparsely } \\
\text { branched }\end{array}$ & $\begin{array}{l}\text { Erect, sparsely } \\
\text { branched }\end{array}$ & $\begin{array}{l}\text { Erect, densely } \\
\text { branched }\end{array}$ \\
\hline Flower shape* & $\begin{array}{l}\text { Single cup- } \\
\text { shaped }\end{array}$ & Single cup-shaped & $\begin{array}{l}\text { Single cup- } \\
\text { shaped }\end{array}$ & $\begin{array}{l}\text { Double camellia-like } \\
\text { shaped }\end{array}$ \\
\hline Number of petals* & 5 & 5 & 5 & 10 \\
\hline Petal size (mm) & $5-18 \times 10-25$ & $5-20 \times 9-26$ & $5-20 \times 10-25$ & $20-22 \times 20-25$ \\
\hline Inflorescence* & Solitary & Solitary & Solitary & $\begin{array}{l}\text { Fascicles in 1-3 } \\
\text { flowers }\end{array}$ \\
\hline Fruit color* & Light green & Light green & Light green & $\begin{array}{l}\text { Deep green in young } \\
\text { stage, light green at } \\
\text { maturity }\end{array}$ \\
\hline Seed size (mm) & $2-3 \times 1.5-2$ & $2-3 \times 1.5-2$ & $2-3 \times 1.5-2$ & $3-4.5 \times 1.5-2.5$ \\
\hline
\end{tabular}

* Taxonomic importance 


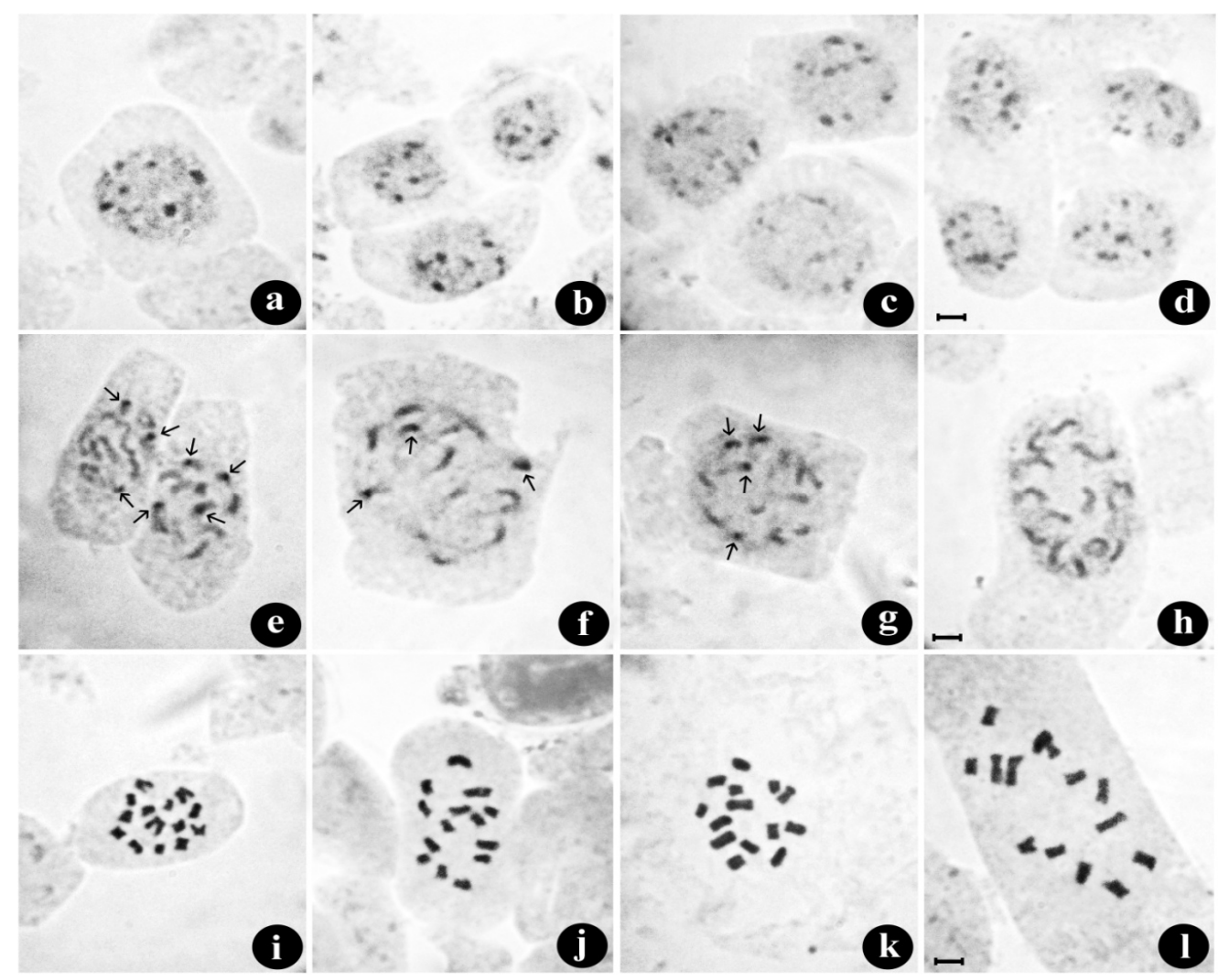

Fig. 2. Orcein-stained interphase, prophase and metaphase stages of mitotic cell division of four floral variants of Impatiens balsamina L. (a) Interphase nuclei of white variant; (b) Interphase nuclei of pink variant; (c) Interphase nuclei of violet variant; (d) Interphase nuclei of red variant; (e) Prophase chromosomes of white variant; (f) Prophase chromosomes of pink variant; (g) Prophase chromosomes of violet variant; (h) Prophase chromosomes of red variant; (i) Metaphase chromosomes of white variant; (j) Metaphase chromosomes of pink variant; (k) Metaphase chromosomes of violet variant; (1) Metaphase chromosomes of red variant (Arrow indicates gradient type). Bar $=5 \mu \mathrm{m}$.

\section{Nature of heterochromatin distribution}

The present study revealed the presence of seven to fourteen prominent darkly stained heterochromatic blocks in the interphase nuclei of four variants of I. balsamina and they were scatteredly distributed (Fig. 2a-d). The prophase chromosomes of red variant were stained homogenously along the entire length of chromosomes, and were considered as 'Continuous Type' (Fig. 2h).
On the other hand, co-existence of continuous and gradient (darker in one end and gradually faint to the other end) types of prophase chromosomes were observed in white, pink and violet variants (Fig. 2e-g). The findings indicated that the facultative heterochromatin were aggregated in the interphase nuclei and then somehow were homogenously or gradually distributed in the prophase chromosomes. 
Table 2. Comparison among four floral variants of Impatiens balsamina L. based on karyomorphological analyses

\begin{tabular}{lllll}
\hline Karyotype parameters & White & Pink & Violet & Red \\
\hline Chromosome number & $2 \mathrm{n}=14$ & $2 \mathrm{n}=14$ & $2 \mathrm{n}=14$ & $2 \mathrm{n}=14$ \\
Centromeric formula & $10 \mathrm{~m}+4 \mathrm{sm}$ & $10 \mathrm{~m}+4 \mathrm{sm}$ & $10 \mathrm{~m}+4 \mathrm{sm}$ & $8 \mathrm{~m}+6 \mathrm{sm}$ \\
Mean centromeric asymmetry & 12.36 & 11.15 & 11.43 & 18.06 \\
Range of chromosomal length $(\mu \mathrm{m})$ & $3.10-4.62$ & $2.73-5.17$ & $2.87-5.28$ & $3.49-5.65$ \\
Total chromosome length $(\mu \mathrm{m})$ & $54.25 \pm 2.09$ & $54.82 \pm 3.14$ & $56.03 \pm 3.32$ & $64.25 \pm 1.56$ \\
Average chromosome length $(\mu \mathrm{m})$ & 3.87 & 3.92 & 4.00 & 4.59 \\
Total Form (TF) value $(\%)$ & 43.28 & 44.38 & 44.18 & 40.58 \\
Karyotype asymmetry index $(\%)$ & 56.72 & 55.62 & 55.82 & 59.42 \\
Karyotype symmetry index $(\%)$ & 76.31 & 79.80 & 79.15 & 68.28 \\
Intrachromosomal asymmetry index & 0.21 & 0.19 & 0.19 & 0.30 \\
Interchromosomal asymmetry index & 0.13 & 0.19 & 0.22 & 0.17 \\
Degree of asymmetry of karyotypes & 0.12 & 0.11 & 0.11 & 0.18 \\
Karyotype category & $1 \mathrm{~A}$ & $1 \mathrm{~A}$ & $1 \mathrm{~A}$ & $1 \mathrm{~A}$ \\
\hline
\end{tabular}

$\mathrm{m}=$ metacentric chromosome, $\mathrm{sm}=$ sub-metacentric chromosome

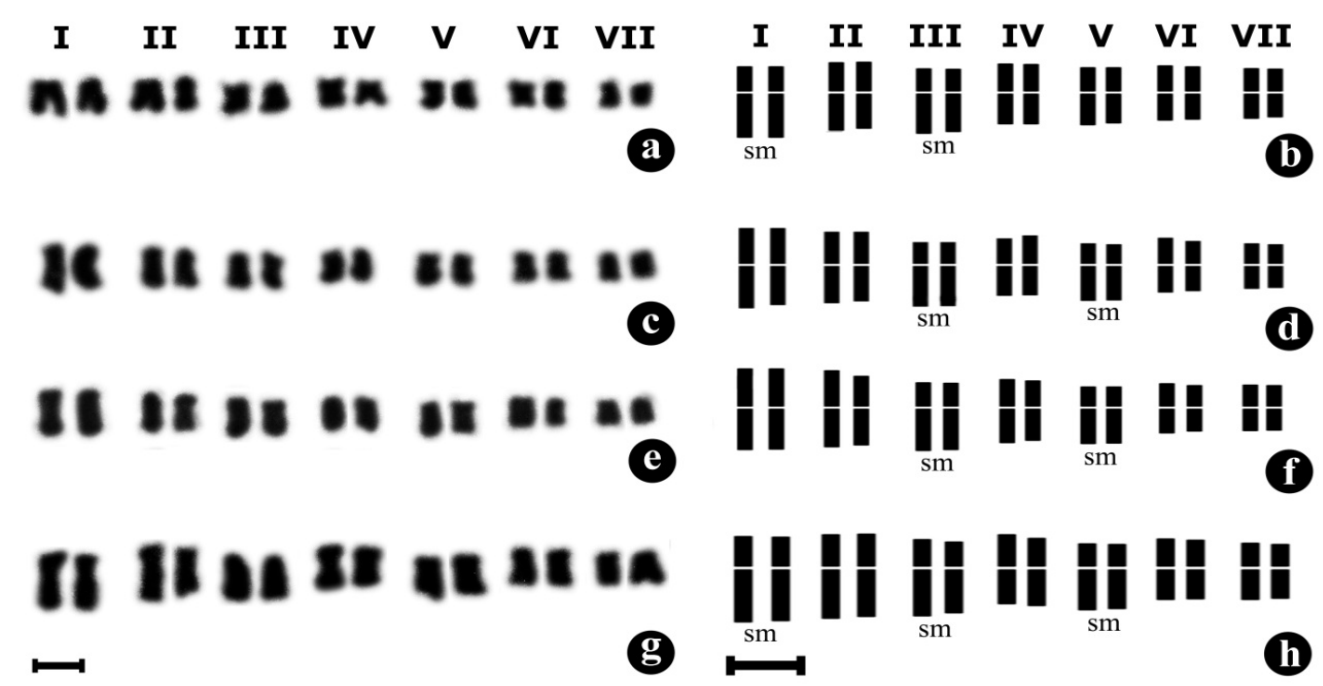

Fig. 3. Karyotype and ideogram made from metaphase chromosomes of four floral variants of Impatiens balsamina L. (a) Karyotype of white variant; (b) Idiogram of white variant; (c) Karyotype of pink variant; (d) Idiogram of pink variant; (e) Karyotype of violet variant; (f) Idiogram of violet variant; (g) Karyotype of red variant; (h) Idiogram of red variant. $\mathrm{sm}=$ sub-metacentric chromosome. Bar $=5 \mu \mathrm{m}$. 


\section{DISCUSSION}

In the present study, we investigated karyomorphological features among four floral variants of I. balsamina and all the variants were found to possess $2 \mathrm{n}=14$ chromosomes with basic chromosome number $\mathrm{x}=7$ (Fig. 2i-1, Table 2 ). The results were found to be consistent with earlier studies, where $2 \mathrm{n}=14$ chromosomes were reported (Sharma 1970, Chaterjee and Sharma 1970, Raghuvanshi and Mahajan 1982, Govindarajan and Subramanian 1986, Huang et al. 1989, Iwatsubo and Naruhashi 1999, Momtaz et al. 2007). However, some other studies showed different somatic chromosome number of $2 \mathrm{n}=12,18,20$ and 24 in I. balsamina (Sharma 1970, Chaterjee and Sharma 1970). If the basic chromosome number of I. balsamina is $\mathrm{x}=6$, then $2 \mathrm{n}=2 \mathrm{x}=12,2 \mathrm{n}=3 \mathrm{x}=$ $18,2 \mathrm{n}=4 \mathrm{x}=24$, which might be regarded as diploid, triploid and tetraploid, respectively. On the other hand, $2 \mathrm{n}=20$ could be originated through aneuploidy.

The staining properties of interphase nuclei and prophase chromosomes sometimes provide additional karyomorphological features that help to characterize different specimens (Tanaka 1971). Darkly stained heterochromatic blocks were observed in the interphase nuclei of all floral variants of I. balsamina (Fig. 2a-d), and this type of staining of interphase nuclei could be regarded as 'Simple Chromocenter Type' (Tanaka 1971). Generally, the localized heterochromatins, as observed in the interphase nuclei are not homogeneously distributed in the prophase chromosomes rather occupy different locations. The present findings did not support the usual regulation regarding distribution of heterochromatin in prophase chromosomes. Presence of facultative heterochromatin might be one of the reasons for this disagreement. Constitutive heterochromatin block along with facultative heterochromatin were found in white, pink and violet variants, whereas most of the heterochromatin were facultative in the red variant. Therefore, four floral variants of
Impatiens balsamina could be categorized on the basis of these characters.

Although all floral variants of I. balsamina were found to possess $2 \mathrm{n}=14$ chromosomes, they differed in many other karyomorphological parameters (Table 2). The centromeric formulae of white, pink and violet variants were $10 \mathrm{~m}+4 \mathrm{sm}$, whereas it was found to be $8 m+6 \mathrm{sm}$ in the red variant. Variation in chromosomal length in these four variants displayed that the largest chromosome was almost double than that of the smallest chromosomes. Therefore, a gradual decrease of chromosomal length was observed in these four Impatiens balsamina variants (Fig. 3). The total chromosome length was nearly similar in white, pink and violet variants, while larger in the red variant. The average chromosomal length and karyotype asymmetry was found bigger in red variant than those of white, pink and violet variants. In contrast, karyotype symmetry was lower in the red variant and relatively higher in white, pink and violet variants (Table 2). The red variant also showed significant higher values in intrachromosomal asymmetry index and degree of asymmetry of karyotypes than the remaining three variants. Results obtained from the present investigation revealed that the white, pink and violet variants shared similar genome indicating a very close relationship cytotaxonomically among them, whereas the red floral variant is distantly related from other variants with cytogenetical dissimilarity.

Though floral variants of I. balsamina employed in this study showed similar morphological characters, but they differed from one another in color and shape of the flowers, inflorescence and pod color characters. Among the studied materials, double camellia-like shaped flower was found in red variant, whereas single cupshaped flowers were evident in rest three variants. In addition, the pod color was darker in red variant than in other three variants (Fig. 1, Table 1). 
According to karyotype analyses, red floral variant showed different heterochromatic condensation nature, distinct centromeric formulae, higher total chromosomal length, higher asymmetry index and lower symmetry index than other three variants (Figs. 2-3, Table 2 ). Karyotype analyses revealed that the white, pink and violet variants of I. balsamina are closely allied and constituted with similar genome. In contrast, the red variant was found to possess slightly modified genome and distinct from the remaining three variants. Differences in various cytological parameters in red floral variant might be correlated with the formation of distinct flower shape (double camellia-like shape) from other floral variants (single cup shape) of Impatiens balsamina. On the basis of morphological characters of taxonomic importance and cytogenetical variation all the four I. balsamina variants could easily be classified into two groups, one with single cup shaped flower and other with double camellialike shaped flower indicating the significance of cytotaxonomical studies of I. balsamina L.

\section{ACKNOWLEDGEMENT}

The financial support from the Ministry of Science and Technology, Government of the People's Republic of Bangladesh for carrying out this study is gratefully acknowledged.

\section{REFERENCES}

Ahmed, Z.U., M.A. Hassan, Z.N.T. Begum, M. Khondker, S.M.H. Kabir, M. Ahmad, A.T.A. Ahmed, A.K.A. Rahman and E.U. Haque. (eds.) 2008. Encyclopedia of Flora and Fauna of Bangladesh. Angiosperms: Dicotyledons (Balsaminaceae-Euphorbiaceae). Vol. 7. Asiatic Society of Bangladesh, Dhaka. pp. 2-6.

Arno, H. 1963. Cytological studies in subfamily Carduoideae (Compositae) of Japan. IX. The karyotype analysis and phylogenetic considerations on Pertya and Ainsliaea. Bot. Mag. 76: 32-39.
Chaterjee, A. and A.K. Sharma. 1970. Chromosome study in Geraniales. Nucleus 13: 179-200.

Dash, C.K., M. Afroz, S.S. Sultana and S.S. Alam. 2017. Conventional and fluorescent karyotype analysis of Ocimum spp. Cytologia 82: 429-434.

Govindarajan, T. and D. Subramanian. 1986. Karyotaxonomy of south Indian Balsaminaceae. Cytologia 51: 107-116.

Greilhuber, J. and F. Speta. 1976. C-banded karyotypes in the Scilla hohenackeri group, S. persica and Puschkinia (Liliaceae). Pl. Syst. Evol. 126: 149-188.

Guerra, M. 2008. Chromosome number in plant cytotaxonomy: concepts and implications. Cytogen. Geno. Res. 120: 339-350.

Huang, S.F., Z.F. Zhao, Z.Y. Chen, S.J. Chen and X.X. Huang. 1989. Chromosome counts on one hundred species and infraspecific taxa. Act. Bot. Aus. Sin. 5: 161-176.

Huziwara, Y. 1962. Karyotype analysis in some genera of Compositae VIII. Further studies on the chromosome of Aster. American J. Bot. 49: 116-119.

Ikeda, H., S. Akiyama, H. Tsukaya, D.M. Mohamed and D. Damaedi. 2005. A cytotaxonomic study of five species of Impatiens (Balsaminaceae) in Java and Borneo, Malesia. J. Japanese Bot. 80: 271-277.

Iwatsubo, Y. and N. Naruhashi. 1999. Karyotypes of three species of Impatiens (Balsaminaceae). J. Phytogeo. Tax. 47: 145-148.

Kang, S.C. and Y. Moon. 1992. Isolation and antimicrobial activity of a naphthoquinone from Impatiens balsamina. Korean $J$. Pharmacog. 23: 240-247.

Kaur, H. 2018. Cytological studies on some members of Commelinaceae Mirb. from Kangra valley (Himachal pradesh) with a 
short summary of karyological data on the analyzed genera. Act. Biol. Crac. Ser. Bot. 60: $95-103$.

Kim, I.S., M.R. Yang, O.H. Lee and S.N. Kang. 2011. Antioxidant activities of hot water extracts from various spices. Int. J. Mol. Sci. 12: 4120-4131.

Lee, O.H. and B.Y. Lee. 2010. Antioxidant and antimicrobial activities of individual and combined phenolics in Olea europaea leaf extract. Biores. Tech. 101: 3751-3754.

Levan, A., K. Fredga and A.A. Sandberg. 1964. Nomenclature for centromeric position on chromosomes. Hereditas 52: 201-220.

Love, A. and D. Love. 1966. Cytotaxonomy of the alpine vascular plants of Mount Washington. Uni. Colora. Stu. Ser. Biol. 24: 1-74.

Meenu, B., E.D. Neeraja, G. Rejimon and A. Varghese. 2015. Impatiens balsamina: An overview. J. Chem. Pharm. Res. 7(9): 1621.

Momtaz, U.S.N., G. Kabir, M.M. Ud-deen and N. Yasmin. 2007. Karyotypic study of seven types of Impatiens balsamina L. J. Bio-Sci. 15: $147-152$.

Peruzzi, L. and H.E. Eroğlu. 2013. Karyotype asymmetry: again, how to measure and what to measure? Comp. Cytogen. 7: 1-9.

Pico, G.M.V.D. and M. Dematteis. 2014. Cytotaxonomy of two species of genus Chrysolaena H. Robinson, 1988 (Vernonieae, Asteraceae) from Northeast Paraguay. Comp. Cytogen. 8: 125-137.

Raghuvanshi, S.S. and S. Mahajan. 1982. Chromosomal associations in B carrier and noncarrier diploid, tetraploid and octoploid Impatiens balsamina L. Proc. Indian Acad. Sci. 48: 147-151.
Sakunphueak, A. and P. Panichayupakaranant. 2012. Comparison of antimicrobial activities of naphthoquinones from Impatiens balsamina. Nat. Prod. Res. 26: 1119-1124.

Sharma, A.K. 1970. Annual Report, 1967-1968. Research Bulletin, University of Calcutta, Cytogenetics Laboratory 2: 1-50.

Stebbins, G.L. 1971. Chromosomal evolution in higher plants. Addison-Wesley publishing company, California, USA. pp. 208.

Sultana, S.S., H. Ara and S.S. Alam. 2011. Karyotype analysis with orcein and CMA in two species of Alocasia (Schott) G. Don. Bangladesh J. Bot. 40: 53-56.

Tanaka, R. 1971. Type of resting nuclei in Orchidaceae. Bot. Mag. 84: 118-122.

Watanabe, K., T. Yahara, T. Denda and K. Kosuge. 1999. Chromosomal evolution in the genus Brachyscome (Asteraceae, Astereae): Statistical tests regarding correlation between changes in karyotype and habit using phylogenetic information. $J$. Pl. Res. 112: 145-161.

Wills, J.C. 1973. A Dictionary of the Flowering Plants and Ferns. $1^{\text {st }}$ Ed. (Revised by Airy Shaw, H.K.). University Press, Cambridge. pp. 56.

Yang, X., D.K. Summerhurst, S.F. Koval, C. Ficker, F.L. Smith and M.A. Bernards. 2001. Isolation of an antimicrobial compound from Impatiens balsamina $\mathrm{L}$. using bioassay-guided fractionation. Phytother. Res. 15: 676-689.

Zarco, C.R. 1986. A new method for estimating karyotype asymmetry. Taxon 35: 526-530.

(Received revised manuscript on 11 December 2018) 